\title{
Antibiotic Usage Reduced Overall Survival by over $70 \%$ in Non-small Cell Lung Cancer Patients on Anti-PD-1 Immunotherapy
}

\author{
KAZUYUKI HAMADA ${ }^{1,2,3}$, KIYOSHI YOSHIMURA ${ }^{1,4}$, YUYA HIRASAWA ${ }^{1}$, MASAHIRO HOSONUMA ${ }^{1,4}$, \\ MASAKAZU MURAYAMA ${ }^{4}$, YOICHIRO NARIKAWA ${ }^{4}$, HIROTSUGU ARIIZUMI ${ }^{1}$, RYOTARO OHKUMA ${ }^{1}$, \\ MIDORI SHIDA ${ }^{4}$, YUTARO KUBOTA ${ }^{1}$, SATOSHI MATSUKUMA ${ }^{1}$, TOMOYUKI ISHIGURO ${ }^{1}$, \\ TAKEHIKO SAMBE ${ }^{5,6}$, ATSUSHI HORIIKE ${ }^{1}$, ATSUO KURAMASU ${ }^{4}$, SATOSHI WADA ${ }^{1,7}$, \\ JUNJI TSURUTANI ${ }^{8}$, EISUKE INOUE ${ }^{9}$, NAOKI UCHIDA ${ }^{5,6}$, YUJI KIUCHI $^{10}$, \\ SHINICHI KOBAYASHI ${ }^{6}$, ROBERT M. HOFFMAN ${ }^{2,3}$ and TAKUYA TSUNODA ${ }^{1}$ \\ ${ }^{1}$ Division of Medical Oncology, Department of Medicine, Showa University School of Medicine, Tokyo, Japan; \\ ${ }^{2}$ Department of Surgery, University of California, San Diego, CA, U.S.A.; \\ ${ }^{3}$ AntiCancer Inc., San Diego, CA, U.S.A.; \\ ${ }^{4}$ Department of Clinical Immuno Oncology, Clinical Research Institute \\ for Clinical Pharmacology and Therapeutics, Showa University, Tokyo, Japan; \\ ${ }^{5}$ Division of Clinical Pharmacology, Department of Pharmacology, \\ Showa University School of Medicine, Tokyo, Japan; \\ ${ }^{6}$ Clinical Research Institute for Clinical Pharmacology and Therapeutics, Showa University, Tokyo, Japan; \\ ${ }^{7}$ Department of Clinical Diagnostic Oncology, Clinical Research Institute \\ for Clinical Pharmacology and Therapeutics, Showa University, Tokyo, Japan; \\ ${ }^{8}$ Advanced Cancer Translational Research Institute, Showa University, Tokyo, Japan; \\ ${ }^{9}$ Research Administration Center, Showa University, Tokyo, Japan; \\ ${ }^{10}$ Department of Pharmacology, Showa University School of Medicine, Tokyo, Japan
}

\begin{abstract}
Background/Aim: There is an increasing use of immunotherapy for non-small cell lung cancer (NSCLC) patients. The present study analysed the effect of antibiotic use on the outcome of NSCLC patients undergoing treatment with anti-programmed cell death-1 (anti-PD-1) immunotherapy. Patients and Methods: This was a retrospective study of 69 NSCLC patients. Eighteen out of 69 patients received antibiotics within 21 days before or within 21 days after start of anti-PD-1 therapy. Results: Patients treated with anti-PD-1 antibodies
\end{abstract}

This article is freely accessible online.

Correspondence to: Kiyoshi Yoshimura, MD, Ph.D., M.O.T., Department of Clinical Immuno Oncology, Clinical Research Institute for Clinical Pharmacology and Therapeutics, Showa University, 6-11-11, Kitakarasuyama, Setagaya-ku, Tokyo 1578577, Japan. Tel: +81 333005256, Fax: +81 333001653, e-mail: kyoshim1@med.showa-u.ac.jp

Key Words: Antibiotics, gut microbiota, immune checkpoint inhibitors, non-small cell lung cancer, survival. receiving antibiotics had greatly decreased objective response rate $(O R R)$, overall survival $(O S)$ and progression-free survival (PFS) compared to those who did not use antibiotics. Multivariate analysis showed that antibiotic treatment of patients on anti-PD-1 antibody therapy was an independent negative predictive factor of PFS; however, it was not a significant independent predictive factor of OS. Conclusion: Use of antibiotics within 21 days before and after anti-PD-1 treatment initiation in patients with NSCLC strongly reduced OS and PFS, suggesting the two treatments should not be combined.

Immunotherapy with anti-programmed cell death-1 (anti-PD1) antibody has been only modestly successful in non-small cell lung cancer (NSCLC) (1). Thus, there is a critical need to identify more effective treatment strategies for anti PD-1 treatment of NSCLC.

Specific intestinal bacteria have been reported to affect the immune system and therapeutic outcome of anti-PD-1 immunotherapy in NSCLC, melanoma, renal cell carcinoma (RCC) and urothelial carcinoma (UC) (2-5). Additionally, the diversity of bacterial flora may also affect the therapeutic outcome of anti-PD-1 immunotherapy (6). 
Certain intestinal bacteria were found to be more prevalent in the good-prognosis group than in the poor-prognosis group of anti-PD-1 immunotherapy. The intestinal bacterium Akkermansia muciniphila increased the efficacy of anti-PD1 treatment of epithelial solid carcinoma (7). Bifidobacterium longum, Collinsella aerofaciens, Enterococcus faecium, and Ruminococcaceae are associated with improved therapeutic outcome of anti-PD-1 immunotherapy in melanoma (8).

Antibiotics alter the composition of the gut microbiota (9, 10). Therefore, it is important to determine if antibiotics affect the outcome of patients treated with immune checkpoint inhibitors (ICIs). In a study investigating the effects of antibiotics in patients with NSCLC, RCC, and UC, the overall survival (OS) and progression-free survival (PFS) was shortened when antibiotics were used within two months before starting treatment with anti-PD-1 antibody (11). In patients with NSCLC, OS was significantly shortened, but PFS showed no difference (12). Conversely, in patients with RCC, OS was not affected by antibiotics but PFS was significantly shortened by antibiotic use (11). In univariate and multivariate Cox regression analyses, antibiotics were an independent negative prognostic predictor of the response to anti-PD-1 treatment of NSCLC and RCC $(11,12)$. Proton pump inhibitors (PPIs) had no effect on OS or PFS. In previous studies, antibiotics were mainly used within one or two months before and/or after the initiation of anti-PD-1 therapy (12-15).

In the present study, we retrospectively investigated the effects of antibiotics on the therapeutic outcome of anti-PD1 treatment of advanced NSCLC. We hypothesized that administration of antibiotics within 21days before or after administration of the first dose of anti-PD-1 antibody would affect the therapeutic outcome of anti-PD-1 treatment. We investigated the effect of administering antibiotics before and after the initial administration of anti-PD-1 antibodies on the response rate, OS, and PFS. In addition. The effects of PPIs and probiotics on anti-PD-1 treatment of patients with NSCLC were also examined.

\section{Patients and Methods}

Patients with NSCLC treated with anti-PD-1 antibody monotherapy at the Oncology Department of Showa University Hospital between January 1, 2016 and December 23, 2019 were retrospectively analyzed. Patients were treated with anti-PD-1 antibody, either nivolumab (OPDIVO $®$, Bristol Myers Squibb, New York, NY, USA) or pembrolizumab (Keytruda ${ }^{\circledR}$, Merck \& Co., Kenilworth, NJ, USA). Patients who had not been evaluated with computed tomography (CT) were excluded. Patients were divided into two groups: those with and those without usage of antibiotics. The patients treated with antibiotics were classified as those who used antibiotics within 21 days before or after anti-PD-1 treatment initiation. For further analysis, the patients were subsequently subdivided as follows: those with or without PPI usage, and those with or without probiotics usage within 21 days before or after the first administration of anti-PD-1 antibody treatment. The present study was performed per the Declaration of Helsinki guidelines and was approved by the Ethics Committee of Showa University School of Medicine (Approval \# 2902).

The Response Evaluation Criteria in Solid Tumors version 1.1 was used to evaluate the objective response rate (ORR) and disease control rate (DCR). PFS was defined as the time from the date of the first anti-PD-1 antibody administration to disease progression or death from any cause. OS was defined as the time from the date of the first anti-PD-1 antibody administration to death from any cause. The Fisher's exact test was used to analyse the ORR and DCR. The Kaplan-Meier method was used to estimate OS and PFS. The $p$-value was calculated using a log-rank test. Multivariate analysis for OS and PFS was performed using the Cox proportional hazards model. The analysis software used for the survival curves was GraphPad Prism 8 (GraphPad Software, Inc., San Diego, CA, USA). Multivariate analyses were performed using JMP Pro 14 (Statistical Analysis System Institute Inc., Cary, NC, USA). A pvalue $\leq 0.05$ was considered significant.

\section{Results}

Effect of antibiotics on the outcome of anti-PD-1 treatment of patients with NSCLC. A total of 70 consecutive patients with advanced NSCLC received anti-PD-1 treatment at Showa University Hospital. Among them, 69 patients were included in the study (Table I). One male patient was excluded because the efficacy of pembrolizumab was not evaluated using CT, and he subsequently died of bacterial pneumonia 28 days after the first administration of anti-PD-1 antibody. The median observation period of patients treated with anti-PD-1 antibody was 251.5 days. Eighteen patients $(26 \%)$ received antibiotics within 21 days before or after the first dose administration of anti-PD-1 antibody (Abx BA21). Nine patients (10.1\%) received antibiotics within 21 days before the first dose administration of anti-PD-1 antibody (Abx B21). Eleven patients $(9 \%)$ received antibiotics within 21 days after the first dose administration of the anti-PD-1 antibody (Abx A21). The ORRs of the Abx BA21 and Abx A21 groups treated with antibiotics were significantly lower than those of the group that did not receive antibiotic pretreatment [partial response $(\mathrm{PR})=2(11.1 \%)$ versus $25(49.0 \%), p=0.005 ; \mathrm{PR}=1 \quad(9 \%)$ versus 15 (45.0\%), $p=0.041$, respectively]. The DCR was significantly lower in the Abx B21 group receiving antibiotics than in the group not receiving antibiotic treatment $(p=0.045$, Figures $1 \mathrm{~A}, \mathrm{~B}$, and $\mathrm{C}$ ).

In the Abx BA21 group, the OS (247 versus 873 days, $p=0.022$, Figure 2A) and PFS (77 versus 239 days, $p<0.001$, Figure 2B) were significantly shorter in patients treated with antibiotics than in those who did not use antibiotics. Thus, antibiotics reduced OS by $72 \%$ and PFS by $68 \%$ in patients treated with antibiotics before or after anti-PD-1 antibody treatment (Abx BA21).

In the Abx B21 group, the OS (183 versus 910 days, respectively, $p<0.001$, Figure 3A) and PFS (71 versus 212 days, respectively, $p=0.007$, Figure $3 \mathrm{~B}$ ) were significantly 
Table I. Characteristics of patients in the study $(n=69)$.

\begin{tabular}{|c|c|c|c|c|}
\hline & $\mathrm{n}=69$ & $\begin{array}{l}\text { Without Abx } \\
\quad(\mathrm{n}=51)\end{array}$ & $\begin{array}{l}\text { With Abx } \\
\quad(\mathrm{n}=18)\end{array}$ & $p$-Value \\
\hline $\begin{array}{l}\text { Median age } \\
\text { (range), y }\end{array}$ & $68(41-81)$ & $68(46-81)$ & $69(41-77)$ & \\
\hline Age $\geq 75$ & 8 & 6 & 2 & 1 \\
\hline Age $<75$ & 61 & 45 & 16 & \\
\hline \multicolumn{5}{|l|}{ Gender, n (\%) } \\
\hline Male & 54 & 40 & 14 & 1 \\
\hline Female & 15 & 11 & 4 & \\
\hline \multicolumn{5}{|l|}{ Smoking status, n (\%) } \\
\hline Current or former & 59 & 42 & 17 & 0.274 \\
\hline Never & 10 & 9 & 1 & \\
\hline \multicolumn{5}{|l|}{ Alcohol, n (\%) } \\
\hline 1 & 30 & 18 & 12 & 0.0549 \\
\hline 0 & 19 & 15 & 4 & \\
\hline NK & 20 & 18 & 2 & \\
\hline \multicolumn{5}{|l|}{ ECOG PS, n (\%) } \\
\hline 0,1 & 63 & 48 & 15 & 0.178 \\
\hline$\geq 2$ & 6 & 3 & 3 & \\
\hline \multicolumn{5}{|l|}{ Histological type, n (\%) } \\
\hline $\mathrm{ADC}$ & 53 & 39 & 14 & 1 \\
\hline $\mathrm{SCC}$ & 15 & 11 & 4 & \\
\hline NOS & 1 & 1 & 0 & \\
\hline \multicolumn{5}{|l|}{ Stage, n (\%) } \\
\hline I & 6 & 4 & 2 & 0.916 \\
\hline II & 3 & 3 & 0 & \\
\hline III & 12 & 9 & 3 & \\
\hline IV & 48 & 35 & 13 & \\
\hline \multicolumn{5}{|l|}{ Treatment line, $\mathrm{n}$} \\
\hline First & 17 & 13 & 4 & 0.537 \\
\hline Second & 29 & 23 & 6 & \\
\hline Third or higher & 23 & 15 & 8 & \\
\hline \multicolumn{5}{|l|}{$\begin{array}{l}\% \text { PD-L1 expression } \\
(22 \mathrm{C} 3), \mathrm{n}(\%)\end{array}$} \\
\hline$\geq 50$ & 29 & 20 & 9 & 0.342 \\
\hline$<50$ & 25 & 21 & 4 & \\
\hline NK & 15 & 10 & 5 & \\
\hline \multicolumn{5}{|l|}{$\operatorname{irAE}$} \\
\hline 1 & 44 & 35 & 9 & 0.169 \\
\hline 0 & 25 & 16 & 9 & \\
\hline \multicolumn{5}{|l|}{$\begin{array}{l}\text { EGFR mutation status, } \\
\mathrm{n}(\%)\end{array}$} \\
\hline Positive & 6 & 5 & 1 & 0.807 \\
\hline Negative & 52 & 37 & 15 & \\
\hline NK & 11 & 9 & 2 & \\
\hline \multicolumn{5}{|l|}{ PPI, n (\%) } \\
\hline 1 & 36 & 25 & 11 & 0.422 \\
\hline 0 & 33 & 26 & 7 & \\
\hline \multicolumn{5}{|l|}{ Probiotics, n (\%) } \\
\hline 1 & 15 & 7 & 8 & 0.0163 \\
\hline 0 & 54 & 44 & 10 & \\
\hline \multicolumn{5}{|l|}{ Antibiotics } \\
\hline Abx B21or A21, n (\%) & 16 & & & \\
\hline $\mathrm{Abx} \mathrm{B} 21, \mathrm{n}(\%)$ & 7 & & & \\
\hline $\mathrm{Abx} A 21, \mathrm{n}(\%)$ & 9 & & & \\
\hline Abx both B21, A21, n & $(\%) 2$ & & & \\
\hline
\end{tabular}

Abx: Antibiotics; Abx A21: treatment with antibiotics within 21 days after initiation of anti-PD-1 antibody treatment; Abx B21: treatment with antibiotics within 21 days before initiation of anti-PD-1 antibody treatment. NK: not known; ECOG: Eastern Cooperative Oncology Group; PS: performance status; PPIs: proton pump inhibitors. shorter in patients who used antibiotics than in those who did not use antibiotics. Thus, antibiotics reduced OS by $80 \%$ and PFS by $67 \%$ in patients treated with with antibiotics within 21 days before anti-PD-1 antibody therapy (Abx B21).

In the Abx A21 group, the difference in OS (undefined versus 873 days, respectively, $p=0.94$, Figure 4A) was not significant, but PFS (65 versus 212 days, respectively, $p=0.04$, Figure 4B) was significantly shorter in patients who were treated with antibiotics than in those who did not use antibiotics. Thus, antibiotics reduced PFS by $69 \%$ in patients treated with anti-PD-1 antibodies within 21 days after initiation of anti-PD-1 antibody therapy. Post-treatment more than 21 days after the initiation of anti-PD-1 antibody therapy with antibiotics did not affect OS and PFS.

No association between the administration of antibiotics and occurrence of immune-related adverse events (irAEs) was observed, including rash, thyroid dysfunction, infusion reaction, radiation pneumonitis, interstitial pneumonia, type 1 diabetes, hypopituitarism, liver damage, or myositis.

Eighteen patients received antibiotics in the present study, and seven types of antibiotics were used in total. Eight patients received oral levofloxacin, four received oral macrolide, six received oral cephem, one received cephem infusion, three received oral trimethoprim-sulfamethoxazole combination, three received carbapenem infusion, and two received tazobactam/piperacillin infusion. The median duration of antibiotics administration was 6 days.

Effect of PPIs and probiotics on the outcome of anti-PD-1 treatment of patients with NSCLC. Eighteen patients (52.2\%) received PPIs within 21 days before and after the first administration of the anti-PD-1 antibody. Compared with patients who did not use PPIs, the differences in ORR and DCR were not significant $(p=0.33, p=0.42$, respectively, Figure 1D). The use of PPIs did not significantly reduce OS or PFS. Moreover, PPIs did not significantly shorten OS (510 versus 910 days, $p=0.28$ ) or PFS (115.5 versus 288 days, $p=0.11$ ) in patients treated with anti-PD-1 antibody (Figure 5).

Fifteen patients $(21.7 \%)$ received probiotics within 21 days before and after the first administration of anti-PD-1 antibody. There were no differences in the ORR and DCR between the group using probiotics and patients not using probiotics ( $p=0.56,0.74$, respectively, Figure $1 \mathrm{E})$. Probiotics did not significantly shorten OS (478 versus 879 days, $p=0.38$ ) or PFS (109 versus 211 days, $p=0.63$ ) in patients treated with anti-PD-1 antibody (Figure 6).

Multivariate analysis of PFS and OS. Multivariate analysis of PFS further supported the fact that administration of antibiotics was associated with unfavorable prognosis in patients treated with anti-PD-1 antibody [hazard ratio 
A Abx BA21

$$
\begin{aligned}
& \text { ORR: } p=0.005 \\
& \text { DCR: } p=0.2116
\end{aligned}
$$

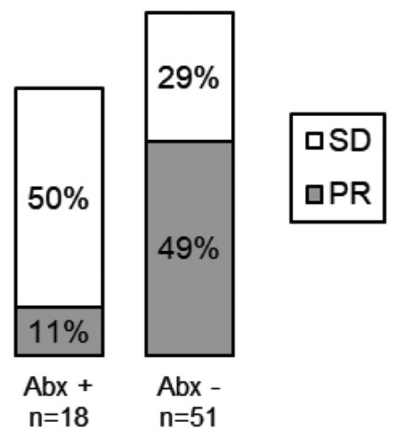

D PPI BA21

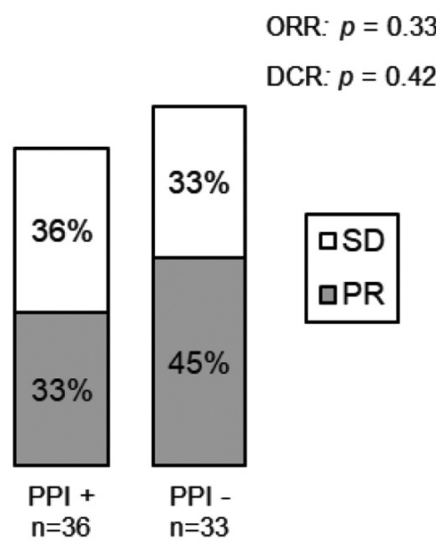

B Abx B21

ORR: $p=0.0793$

DCR: $p=0.045$

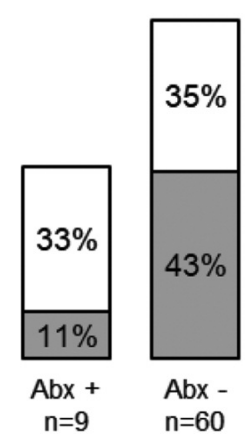

C Abx A21

ORR: $p=0.041$

DCR: $p>0.9999$

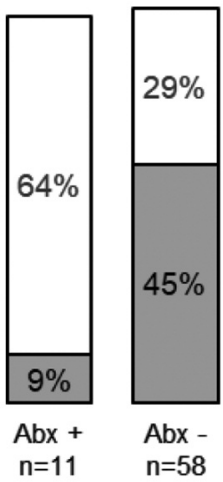

口SD

$\square P R$

\section{E Probiotics BA21}

ORR: $p=0.56$

DCR: $p=0.74$

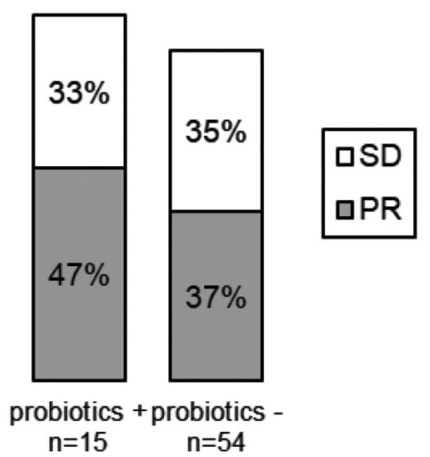

Figure 1. The overall response rate (ORR) and disease control rate (DCR) to anti-programmed cell death -1 (PD-1) antibody. (A) Abx BA21, patients who received antibiotics within 21 days before or after anti-PD-1 antibody treatment $(B) A b x B 21$, patients who received antibiotics within 21 days before initiation of anti-PD-1 antibody treatment $(C)$ Abx A21, patients who received antibiotics within 21 days after initiation of treatment with anti-PD-1 antibody. (D) Patients who received a proton pump inhibitor (PPI), within 21 days before and after initiation of anti-PD-1 antibody (BA21). (E) Patients treated with probiotics within 21 days before or after anti-PD-1 antibody therapy. ORR: Objective response rate; DCR: disease control rate; SD: stable disease; PR: partial response.

$(\mathrm{HR})=3.16,95 \%$ confidence interval $(\mathrm{CI})=1.55-6.25$, $p=0.002]$. Administration of antibiotics was an independent risk factor of PFS (Table II). Multivariate analysis of OS showed that antibiotics, PPIs, and probiotics were not associated with an unfavorable prognosis. The HRs were $1.99(95 \% \mathrm{CI}=0.91-4.09, p=0.082)$ for the use of antibiotics, $1.44(95 \% \mathrm{CI}=0.69-3.02, p=0.33)$ for the use of PPIs, and 1.37 for the use of probiotics $(95 \% \mathrm{CI}=0.57-3.05, p=0.46)$. Male gender and Eastern Cooperative Oncology Group performance status were prognostic factors of patients with NSCLC treated with PD-1 antibody (Table II).

\section{Discussion}

Several previous studies have assessed the efficacy of anti-PD1 antibody therapy with or without antibiotic treatment in patients with NSCLC $(11,12,16)$. The results of such studies suggested that antibiotics worsen OS and PFS in patients taking anti-PD-1 antibody. In a previous study, the PFS of patients with malignant melanoma who received antibiotics within 30 days of starting treatment with anti-PD-1 antibody was shortened, but the difference in OS was not significant (13). In the present study antibiotics significantly reduced OS and PFS. 
A

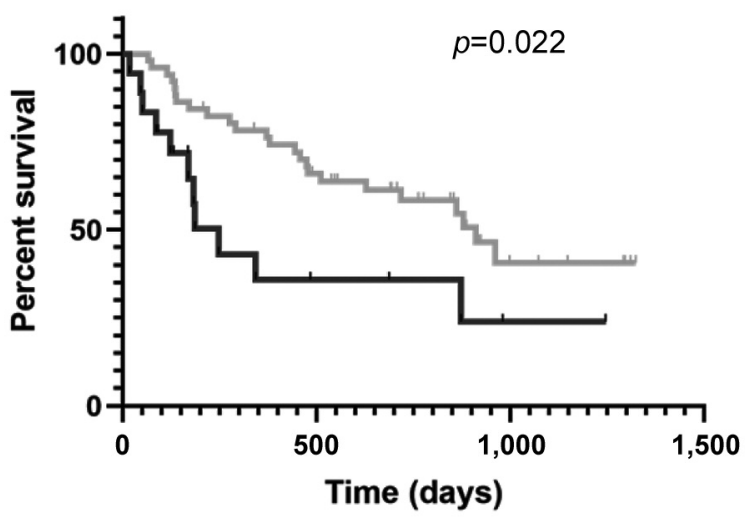

B

Abx BA21 PFS

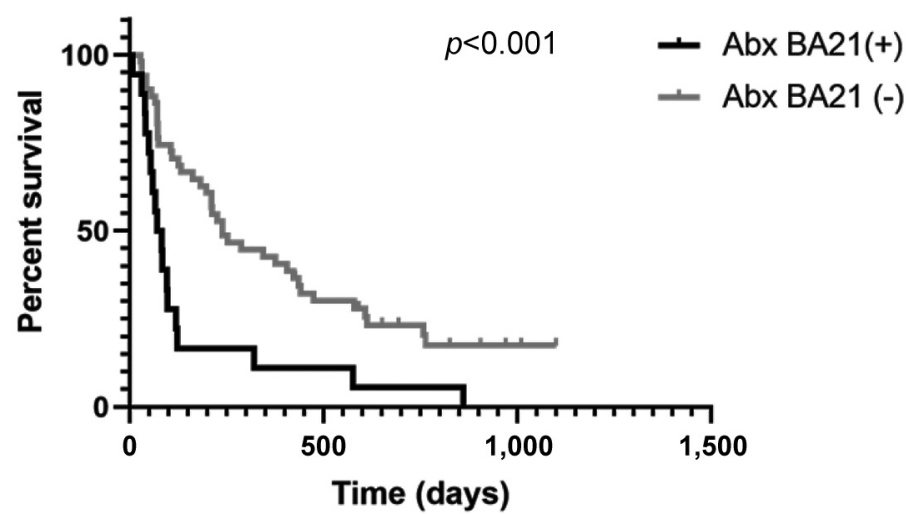

Figure 2. Survival curves and the impact of antibiotics on patients treated with anti-programmed cell death-1 (PD-1) antibody before or after initiation of treatment. Kaplan-Meier curves showing (A) overall survival $(O S)$ and $(B)$ and progression-free survival (PFS) following anti-PD-1 antibody therapy. Abx BA21: Patients who received antibiotics within 21 days before or until 21 days after anti-PD-1 antibody initiation.

A

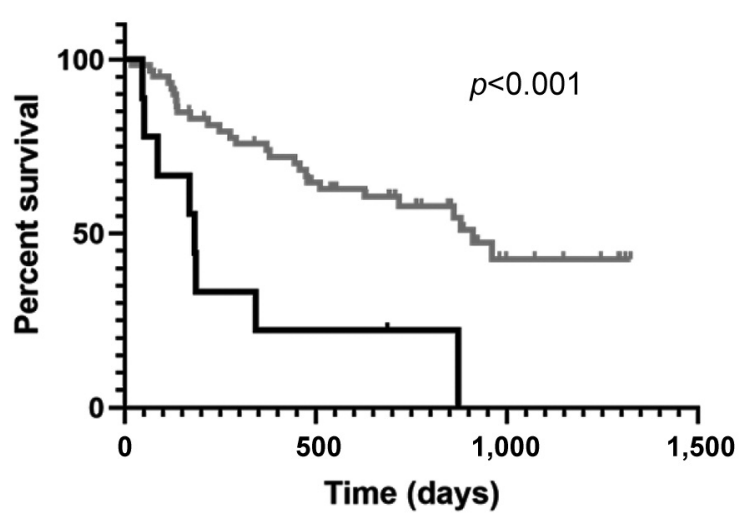

B

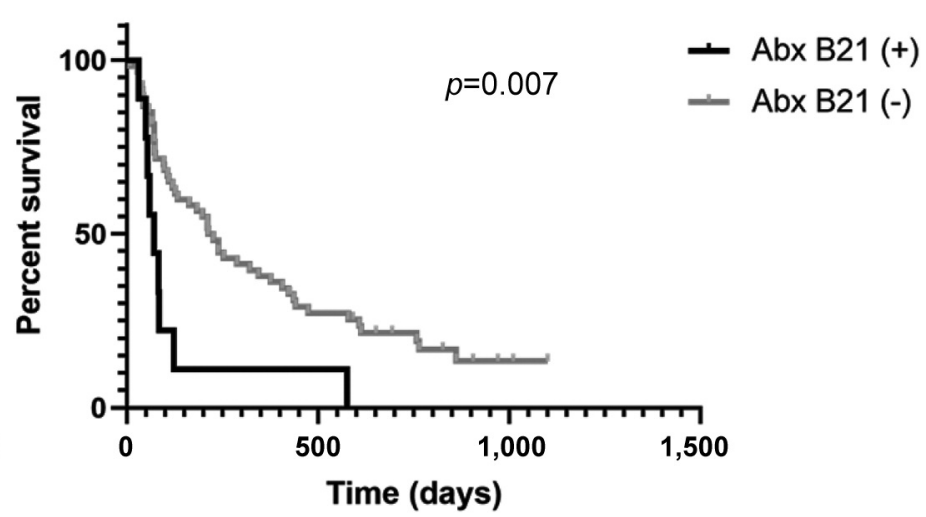

Figure 3. Survival curves and the impact of antibiotics on patients treated with anti-programmed cell death-1 (PD-1) antibody using antibiotics within 21 days before anti-PD-1 antibody initiation. Kaplan-Meier curves showing (A) overall survival (OS) and (B) progression-free survival (PFS) following anti-PD-1 antibody therapy. Abx B21: patients receiving antibiotics within 21 days before anti-PD-1 antibody therapy.

In the present study, both OS and PFS were significantly reduced by antibiotic administration within 21 days before initiation of the administration of anti-PD-1 antibody. PFS but not OS was significantly reduced by antibiotic use within 21 days after the initiation of anti-PD-1 antibody treatment.

The composition and diversity of the gut microbiota before starting treatment with ICIs affects therapeutic efficacy $(6,8)$. Previous meta-analysis supports the idea that the effect of antibiotics on the outcome of ICI immunotherapies depends on the time of administration (16). In a previous study, antibiotics were significantly detrimental to the efficacy of ICI immunotherapy when administrated between -60 and +60 days from the initiation of treatment. Administration of antibiotics later than 60 days from the initiation of treatment did not affect survival (16). In the present study, the median duration of antibiotics administration was 6 days. The results suggested that shortterm administration of antibiotics had a significant effect on the efficacy of anti-PD-1 immunotherapy.

As with antibiotics, PPIs modify the gut microbiota. Oral microbiota can quickly enter the intestine because PPIs increase the $\mathrm{pH}$ in the stomach. Thus, the 

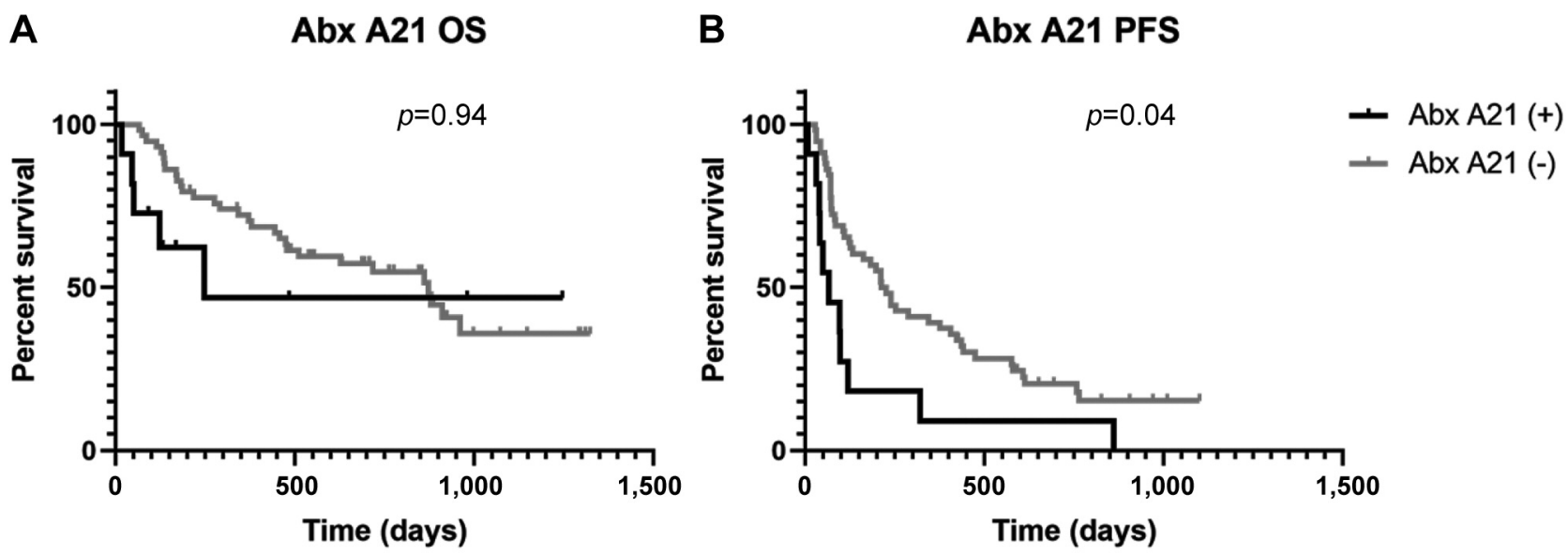

Figure 4. Survival curves of patients treated with anti-programmed cell death-1 (PD-1) antibody using antibiotics (PFS) 21 days after anti-PD-1 antibody initiation. Kaplan-Meier curves showing (A) overall survival (OS) and (B) progression-free survival (PFS) following anti-PD-1 antibody therapy. Abx A21: Patients who received antibiotics 21 days after anti-PD-1 antibody initiation.

A

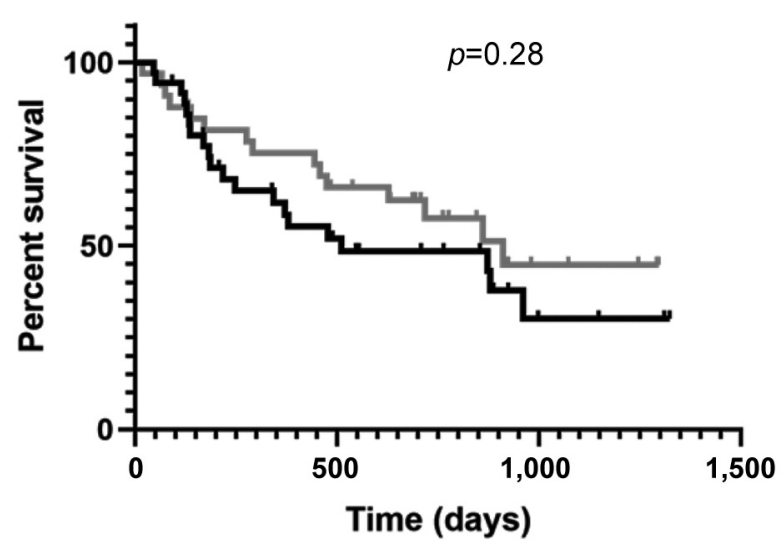

B

PPI PFS

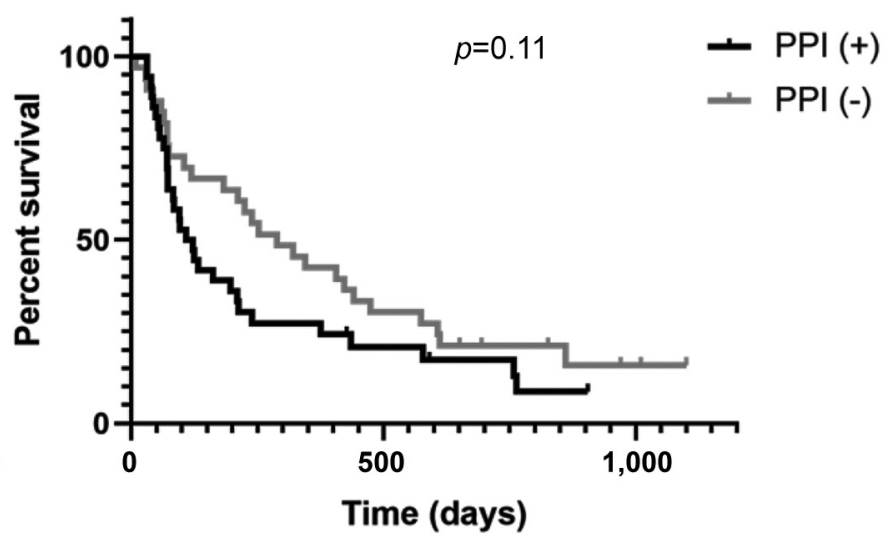

Figure 5. Survival curves and the impact of a proton pump inhibitor (PPI) on patients (PFS) treated with anti-programmed cell death (PD-1) antibody. Kaplan-Meier curves showing (A) overall survival (OS) and (B) progression-free survival (PFS) following anti-PD-1 antibody therapy.

composition of the gut microbiota changes and the diversity decreases. The association between the microbiome and treatment with PPIs is independent of the dose of antibiotics administered (17). In a previous study, PPIs reduced the efficacy of the anti-PD-L1 antibody atezolizumab (18). However, there are other reports stating that PPIs did not affect the outcome of treatment with ICIs. In the present study, the use of PPIs did not significantly reduce OS and PFS. It has been previously shown that probiotics do not cause significant changes to the gut microbiota (19-21). In the present study, probiotics did not affect the therapeutic outcome of ICIs possibly due to the high levels of Bifidobacterium found in some Japanese patients compared to patients from the United States and Europe (22).

The present study has the limitation that it is retrospective; A further prospective study that investigates the effects of antibiotics on the therapeutic outcome of ICIs is required. The results of the present study, however, indicate that the use of antibiotics within the indicated time periods of antiPD-1 therapy is contraindicated.

\section{Conflicts of Interest}

The Authors have no conflicts of interest to declare in relation to this study. 
A

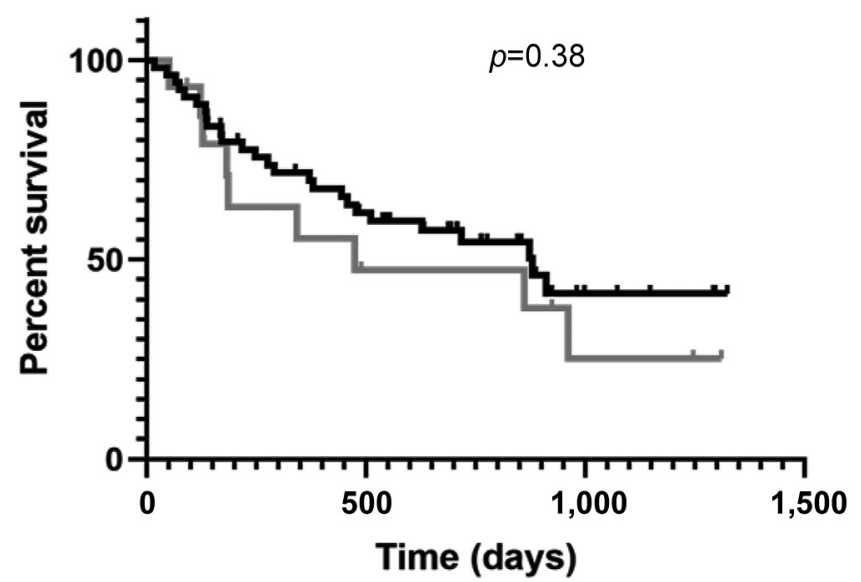

B

Probiotics PFS

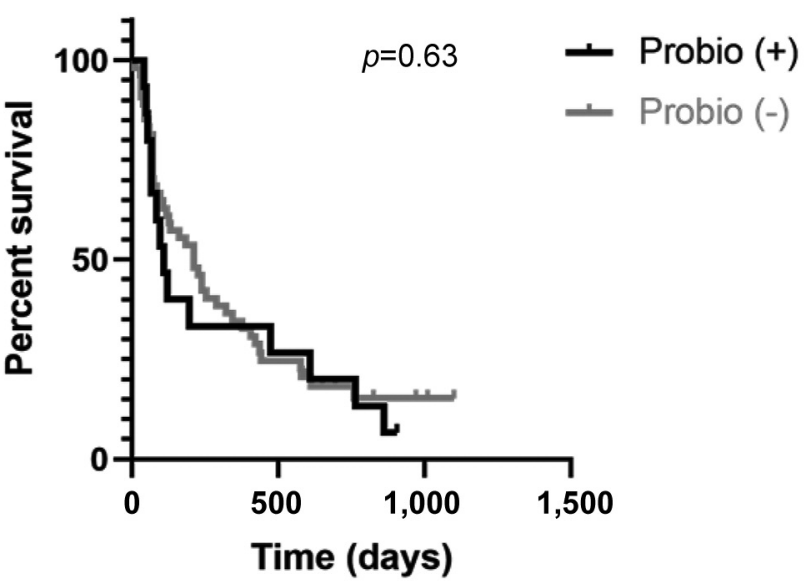

Figure 6. Survival curves and the impact of probiotics on patients treated with anti-programmed cell death (PD-1) antibody. Kaplan-Meier curves showing (A) overall survival (OS) and (B) progression-free survival (PFS) following anti-PD-1 antibody therapy. Probiotics: Patients who received probiotics during the period of 21 days before until 21 days after initiation of anti-PD-1 antibody treatment. Probio: probiotics.

Table II. Univariate and multivariate analyses of clinical parameters for progression-free survival (PFS) and overall survival (OS).

\begin{tabular}{lccc}
\hline \multicolumn{4}{l}{ Multivariate analysis of clinical parameters on PFS } \\
\hline Factor & HR & $95 \%$ CI & $p$-Value \\
\hline Abx BA21 & 3.16 & $1.55-6.25$ & 0.002 \\
PPI BA21 & 1.71 & $0.88-3.31$ & 0.112 \\
Probiotics BA21 & 0.71 & $0.31-1.51$ & 0.377 \\
ECOG PS ( $\geq 2)$ & 1.81 & $0.63-4.51$ & 0.250 \\
EGFR (positive) & 2.37 & $0.86-5.59$ & 0.091
\end{tabular}

\begin{tabular}{lccc}
\hline \multicolumn{4}{l}{ Multivariate analysis of clinical parameters on OS } \\
\hline Factor & HR & $95 \%$ CI & $p$-Value \\
\hline Abx BA21 & 1.99 & $0.91-4.09$ & 0.082 \\
PPI BA21 & 1.44 & $0.69-3.02$ & 0.328 \\
Probiotics BA21 & 1.37 & $0.57-3.05$ & 0.464 \\
ECOG PS ( $\geq 2)$ & 4.58 & $1.20-14.7$ & 0.028 \\
Gender (male) & 3.79 & $1.41-13.4$ & 0.006 \\
\hline
\end{tabular}

Abx: Antibiotics; PPI: proton pump inhibitor; ECOG: Eastern Cooperative Oncology Group; PS: performance status; BA21: treatment with either antibiotics, protein pump inhibitors or probiotics 21 days before or after initiation of anti-PD-1 antibody treatment. PFS: progression-free survival; OS: overall survival; EGFR: epidermal growth factor receptor; HR: hazard ratio; CI: confidence interval.

Table III. Overall survival in the studies of patients receiving antibiotics and the efficacy of immune check point inhibitors (ICI) in NSCLC.

\begin{tabular}{|c|c|c|c|c|}
\hline & Derosa et al. $(\mathrm{n}=239)$ & Zhao et al. $(\mathrm{n}=109)$ & Kim et al. $(\mathrm{n}=131)$ & Present study $(n=69)$ \\
\hline Abx use, n (\%) & $48(20.1)$ & $20(18.3 \%)$ & $60(45.8 \%)$ & $18(26 \%)$ \\
\hline $\begin{array}{l}\text { Time of Abx treatment before or } \\
\text { after to the initiation of ICIs, (days) }\end{array}$ & -30 & -30 to 30 & -60 & -21 to 21 \\
\hline $\begin{array}{l}\text { Median OS, (months) (Abx-treated versus } \\
\text { Abx-untreated) }\end{array}$ & $7.9 v s .24 .6$ & 6.07 vs. 21.87 & 4 vs. 22 & 8.12 vs. 28.7 \\
\hline
\end{tabular}

Abx: Antibiotics; OS: overall survival; NSCLC: non small cell lung cancer.

\section{Authors' Contributions}

K.H. and K.Y. designed, performed investigation, analyzed data, and wrote the paper; Y.H., M.H., R.O., MS, Y.K., S.M., and T.I. collected the clinical data of the patients and gave technical support.; TS, AH, AK, SW, JT, NU, YK, SK, R.M.H., and TT. supervised the findings of this work and reviewed the manuscript.; E.I. supervised the statistical analysis. 


\section{Acknowledgements}

The Authors wish to thank Ms. Manami Kobayashi and Editage for editing and reviewing this manuscript and Ms. Ayako Hamada for support.

\section{References}

1 Larkin J, Chiarion-Sileni V, Gonzalez R, Grob JJ, Rutkowski P, Lao CD, Cowey CL, Schadendorf D, Wagstaff J, Dummer R, Ferrucci PF, Smylie M, Hogg D, Hill A, Márquez-Rodas I, Haanen J, Guidoboni M, Maio M, Schöffski P, Carlino MS, Lebbé C, McArthur G, Ascierto PA, Daniels GA, Long GV, Bastholt L, Rizzo JI, Balogh A, Moshyk A, Hodi FS and Wolchok JD: Fiveyear survival with combined nivolumab and ipilimumab in advanced melanoma. N Engl J Med 381(16): 1535-1546, 2019. PMID: 31562797. DOI: 10.1056/NEJMoa1910836

2 Sivan A, Corrales L, Hubert N, Williams JB, Aquino-Michaels K, Earley ZM, Benyamin FW, Lei YM, Jabri B, Alegre ML, Chang EB and Gajewski TF: Commensal Bifidobacterium promotes antitumor immunity and facilitates anti-PD-L1 efficacy. Science 350(6264): 1084-1089, 2015. PMID: 26541606. DOI: $10.1126 /$ science.aac4255

3 Hooper LV, Littman DR and Macpherson AJ: Interactions between the microbiota and the immune system. Science 336(6086): 1268-1273, 2012. PMID: 22674334. DOI: $10.1126 /$ science 1223490

4 Vétizou M, Pitt JM, Daillère R, Lepage P, Waldschmitt N, Flament C, Rusakiewicz S, Routy B, Roberti MP, Duong CP, Poirier-Colame V, Roux A, Becharef S, Formenti S, Golden E, Cording S, Eberl G, Schlitzer A, Ginhoux F, Mani S, Yamazaki $\mathrm{T}$, Jacquelot $\mathrm{N}$, Enot DP, Bérard M, Nigou J, Opolon P, Eggermont A, Woerther PL, Chachaty E, Chaput N, Robert C, Mateus C, Kroemer G, Raoult D, Boneca IG, Carbonnel F, Chamaillard $\mathrm{M}$ and Zitvogel L: Anticancer immunotherapy by CTLA-4 blockade relies on the gut microbiota. Science 350(6264): 1079-1084, 2015. PMID: 26541610. DOI: 10.1126/ science.aad 1329

5 Fessler J, Matson V and Gajewski TF: Exploring the emerging role of the microbiome in cancer immunotherapy. J Immunother Cancer 7(1): 108, 2019. PMID: 30995949. DOI: 10.1186/ s40425-019-0574-4

6 Gopalakrishnan V, Spencer CN, Nezi L, Reuben A, Andrews MC, Karpinets TV, Prieto PA, Vicente D, Hoffman K, Wei SC, Cogdill AP, Zhao L, Hudgens CW, Hutchinson DS, Manzo T, Petaccia de Macedo M, Cotechini T, Kumar T, Chen WS, Reddy SM, Szczepaniak Sloane R, Galloway-Pena J, Jiang H, Chen PL, Shpall EJ, Rezvani K, Alousi AM, Chemaly RF, Shelburne S, Vence LM, Okhuysen PC, Jensen VB, Swennes AG, McAllister F, Marcelo Riquelme Sanchez E, Zhang Y, Le Chatelier E, Zitvogel L, Pons N, Austin-Breneman JL, Haydu LE, Burton EM, Gardner JM, Sirmans E, Hu J, Lazar AJ, Tsujikawa T, Diab A, Tawbi H, Glitza IC, Hwu WJ, Patel SP, Woodman SE, Amaria RN, Davies MA, Gershenwald JE, Hwu P, Lee JE, Zhang J, Coussens LM, Cooper ZA, Futreal PA, Daniel CR, Ajami NJ, Petrosino JF, Tetzlaff MT, Sharma P, Allison JP, Jenq RR and Wargo JA: Gut microbiome modulates response to anti-PD-1 immunotherapy in melanoma patients. Science 359(6371): 97-103, 2018. PMID: 29097493. DOI: 10.1126/science.aan4236
7 Routy B, Le Chatelier E, Derosa L, Duong CPM, Alou MT, Daillère R, Fluckiger A, Messaoudene M, Rauber C, Roberti MP, Fidelle M, Flament C, Poirier-Colame V, Opolon P, Klein C, Iribarren K, Mondragón L, Jacquelot N, Qu B, Ferrere G, Clémenson C, Mezquita L, Masip JR, Naltet C, Brosseau S, Kaderbhai C, Richard C, Rizvi H, Levenez F, Galleron N, Quinquis B, Pons N, Ryffel B, Minard-Colin V, Gonin P, Soria JC, Deutsch E, Loriot Y, Ghiringhelli F, Zalcman G, Goldwasser F, Escudier B, Hellmann MD, Eggermont A, Raoult D, Albiges L, Kroemer G and Zitvogel L: Gut microbiome influences efficacy of PD-1-based immunotherapy against epithelial tumors. Science 359(6371): 91-97, 2018. PMID: 29097494. DOI: 10.1126/science.aan3706

8 Matson V, Fessler J, Bao R, Chongsuwat T, Zha Y, Alegre ML, Luke JJ and Gajewski TF: The commensal microbiome is associated with anti-PD-1 efficacy in metastatic melanoma patients. Science 359(6371): 104-108, 2018. PMID: 29302014. DOI: $10.1126 /$ science.aao3290

9 Modi SR, Collins JJ and Relman DA: Antibiotics and the gut microbiota. J Clin Invest 124(10): 4212-4218, 2014. PMID: 25271726. DOI: 10.1172/JCI72333

10 Langdon A, Crook N and Dantas G: The effects of antibiotics on the microbiome throughout development and alternative approaches for therapeutic modulation. Genome Med 8(1): 39, 2016. PMID: 27074706. DOI: 10.1186/s13073-016-0294-z

11 Derosa L, Hellmann MD, Spaziano M, Halpenny D, Fidelle M, Rizvi H, Long N, Plodkowski AJ, Arbour KC, Chaft JE, Rouche JA, Zitvogel L, Zalcman G, Albiges L, Escudier B and Routy B: Negative association of antibiotics on clinical activity of immune checkpoint inhibitors in patients with advanced renal cell and non-small-cell lung cancer. Ann Oncol 29(6): 1437-1444, 2018. PMID: 29617710. DOI: 10.1093/annonc/mdy 103

12 Zhao S, Gao G, Li W, Li X, Zhao C, Jiang T, Jia Y, He Y, Li A, Su C, Ren S, Chen X and Zhou C: Antibiotics are associated with attenuated efficacy of anti-PD-1/PD-L1 therapies in Chinese patients with advanced non-small cell lung cancer. Lung Cancer 130: 10-17, 2019. PMID: 30885328. DOI: 10.1016/ j.lungcan.2019.01.017

13 Elkrief A, El Raichani L, Richard C, Messaoudene M, Belkaid W, Malo J, Belanger K, Miller W, Jamal R, Letarte N, Wong P and Routy B: Antibiotics are associated with decreased progression-free survival of advanced melanoma patients treated with immune checkpoint inhibitors. Oncoimmunology 8(4): e1568812, 2019. PMID: 30906663. DOI: 10.1080/2162402X. 2019.1568812

14 Tinsley N, Zhou C, Tan G, Rack S, Lorigan P, Blackhall F, Krebs M, Carter L, Thistlethwaite F, Graham D and Cook N: Cumulative antibiotic use significantly decreases efficacy of checkpoint inhibitors in patients with advanced cancer. Oncologist 25(1): 55-63, 2020. PMID: 31292268. DOI: 10.1634/ theoncologist.2019-0160

15 Pinato DJ, Howlett S, Ottaviani D, Urus H, Patel A, Mineo T, Brock C, Power D, Hatcher O, Falconer A, Ingle M, Brown A, Gujral D, Partridge S, Sarwar N, Gonzalez M, Bendle M, Lewanski C, Newsom-Davis T, Allara E and Bower M: Association of prior antibiotic treatment with survival and response to immune checkpoint inhibitor therapy in patients with cancer. JAMA Oncol 5(12): 1774-1778, 2019. PMID: 31513236. DOI: $10.1001 /$ jamaoncol.2019.2785 
16 Lurienne L, Cervesi J, Duhalde L, de Gunzburg J, Andremont A, Zalcman G, Buffet $\mathrm{R}$ and Bandinelli PA: nsclc immunotherapy efficacy and antibiotic use: a systematic review and meta-analysis. J Thorac Oncol 15(7): 1147-1159, 2020. PMID: 32173463. DOI: 10.1016/j.jtho.2020.03.002

17 Imhann F, Bonder MJ, Vich Vila A, Fu J, Mujagic Z, Vork L, Tigchelaar EF, Jankipersadsing SA, Cenit MC, Harmsen HJ, Dijkstra G, Franke L, Xavier RJ, Jonkers D, Wijmenga C, Weersma RK and Zhernakova A: Proton pump inhibitors affect the gut microbiome. Gut 65(5): 740-748, 2016. PMID: 26657899. DOI: 10.1136/gutjnl-2015-310376

18 Chalabi M, Cardona A, Nagarkar DR, Dhawahir Scala A, Gandara DR, Rittmeyer A, Albert ML, Powles T, Kok M, Herrera FG and imCORE working group of early career investigators: Efficacy of chemotherapy and atezolizumab in patients with non-small-cell lung cancer receiving antibiotics and proton pump inhibitors: pooled post hoc analyses of the OAK and POPLAR trials. Ann Oncol 31(4): 525-531, 2020. PMID: 32115349. DOI: $10.1016 / j$.annonc.2020.01.006

19 Hemarajata P and Versalovic J: Effects of probiotics on gut microbiota: mechanisms of intestinal immunomodulation and neuromodulation. Therap Adv Gastroenterol 6(1): 39-51, 2013. PMID: 23320049. DOI: 10.1177/1756283X12459294
20 Odamaki T, Kato K, Sugahara H, Xiao JZ, Abe F and Benno Y: Effect of probiotic yoghurt on animal-based diet-induced change in gut microbiota: an open, randomised, parallel-group study. Benef Microbes 7(4): 473-484, 2016. PMID: 27133564. DOI: 10.3920/BM2015.0173

21 Scott KP, Antoine JM, Midtvedt $\mathrm{T}$ and van Hemert S: Manipulating the gut microbiota to maintain health and treat disease. Microb Ecol Health Dis 26: 25877, 2015. PMID: 25651995. DOI: $10.3402 /$ mehd.v26.25877

22 Kato K, Ishida S, Tanaka M, Mitsuyama E, Xiao JZ and Odamaki T: Association between functional lactase variants and a high abundance of Bifidobacterium in the gut of healthy Japanese people. PLoS One 13(10): e0206189, 2018. PMID: 30339693. DOI: 10.1371/journal.pone.0206189
Received July 29, 2021

Revised August 22, 2021

Accepted August 23, 2021 